\title{
ROLE OF EXOGENOUS APPLICATION OF ALPHA-TOCOPHEROL IN REDUCING LOW TEMPERATURE STRESS IN BELL PEPPER
}

\author{
aMuhammad Atiq, bSameen Adil, aNasir A. Rajput, aShahbaz Talib Sahi, cAkhtar Hameed, dAbdul Jabbar,

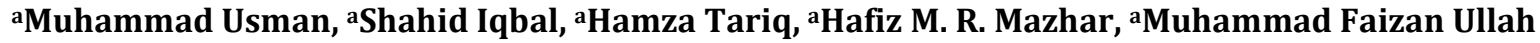 \\ a Department of Plant Pathology, Faculty of Agriculture,University of Agriculture, Faisalabad, Pakistan. \\ ${ }^{b}$ Department of Botany, Faculty of Basic Sciences, University of Agriculture, Faisalabad, Pakistan. \\ c Department of Agronomy, PARAS Campus, Community College, University of Agriculture, Faisalabad, Pakistan. \\ d Department of Plant Protection, MNS University, Old Shujabad Road, Multan, Pakistan.
}

\section{A R T I C L E I N F O}

\section{Article History}

Received: May 18, 2021

Revised: August 25, 2021

Accepted: September 30, 2021

\section{Keywords}

Capsicum

Alpha-Tocopherol

low temperature stress

antioxidants
A B S T R A C T

Changing climatic conditions have an impact on the commercial harvest and production of Capsicum annuum L. across the world. It is a summer crop that grows best at $21^{\circ} \mathrm{C}$ (low) to $37{ }^{\circ} \mathrm{C}$ (high) temperature. Changes in normal growth, poor shoot and root length, increased antioxidant activity, low sugar content, high proline content, and poor yield were observed in bell pepper at low temperature stress. A research trial was conducted on bell peppers in the Department of Plant Pathology at University of Agriculture, Faisalabad. Bell peppers were cultivated hydroponically and alpha-tocopherol control $(0 \mathrm{ppm}), 25 \mathrm{ppm}, 50 \mathrm{ppm}$, and $100 \mathrm{ppm}$ were applied in foliar application. At the reproductive period, a low temperature stress of $18{ }^{\circ} \mathrm{C}$ day and $15{ }^{\circ} \mathrm{C}$ night was used given. After seven days of foliar spray, plants were exposed to cold temperatures during the day and night. After seven days of stress, the plants were harvested and morphological, physiological, and biochemical data were examined. Plant growth, leaf area, number of leaves, buds, and flowers, photosynthetic pigments, relative water content, cell membrane permeability, total soluble sugar, total reducing sugar, protein contents, and total free amino acid levels were all reduced when exposed to high temperatures. When the stress of low temperature was applied, there was a rise in proline, phenolic, flavonoid, H2O2, MDA, enzymatic antioxidants SOD, CAT, POD, and in APX. Under temperature stress, foliar application of alpha-tocopherol significantly improved CAT, POD, APX activity, decreased MDA, H2O2, and improved proline content. Exogenously administered alpha-tocopherol was found to be effective in boosting capsicum growth and antioxidant capability under low temperature stress.

Corresponding Author: Muhammad Atiq

Email:dratiq1@yahoo.com

(C) The Author(s) 2021.

\section{INTRODUCTION}

Capsicum annuum L. belongs to the family solanacea, genus capsicum, locally known as bell pepper, Shimla Mirch or sweet pepper, used as a food worldwide. It contains vitamins A, B, C, E, B6, thiamine, beta-carotene, proteins, iron, and $\mathrm{Ca}^{2}+$, which are good for human health. It is a large-sized fruit which is cultivated almost around the world (Shrestha et al., 2014; Ali et al., 2016; Kantar et al., 2016; Khan et al., 2017). Capsicum in Pakistan is an economically important cash crop and is cultivated on $19 \%$ area available for vegetable cultivation (Shah et al., 2009). The economic survey of Pakistan during 20132014 found that the area available for cultivation was 62.7 thousand ha, with 145.8 thousand tonnes of production 
annually (Qureshi et al., 2015).

Environmental stress causes damage to the plants and poses a major threat to food production. It alters the plant morphology, physiology, biochemistry, rate of metabolism, and photosynthesis in C3 and C4 plants (Liu et al., 2001; Wang et al., 2003; Jing et al., 2016). Low temperatures enhance photorespiration, leaf senescence, alter gene function, retard growth, reduce productivity, biological mechanisms, plant height, biomass, and yield. Under low temperatures, reactive oxygen species (ROS) increase in plants that damage the cell membranes, and plants die due to oxidative stress (Li et al., 2004; Wang and Liu, 2010; Zhai et al., 2016).

Capsicum is highly temperature sensitive crop and low temperature $\left(14^{\circ} \mathrm{C}\right)$ severely disturbs its physiology that results in decreased growth of leaves, buds, and flower, reduced metabolism and cell function, irregular shedding of vegetative and reproductive parts, accumulation of ROS that lead to lipid and protein degradation, abnormal sex organ and feasible pollen grain, swollen and enlarged ovaries, parthenocarpic and abnormal fruit size and poor yield (Mateos et al., 2013; Pyshnaya et al., 2016). Application of antioxidants is one of the leading remedies to reduce stress, improve quality, growth, and yield. Vitamins are antioxidants, natural bio-regulators, essential organic compounds, part of enzymatic reaction as cofactors. A small amount is effective as well as essential for living organism's metabolisms and their deficiency leads to poor yield (Oertli, 1987; Sadak, 2014).

Vitamins (folic acid, vitamin A, B12, B6, B2, B1, C, D, E, K, $\mathrm{H}$, pantothenic acid) are applied as foliar, priming agents, rooting medium and to eliminate stress, protect the plant, scavenge reactive oxygen species and initiate root and flower development (Sadiq et al., 2017). PSII is protected from photo-inactivation by alpha-tocopherol (vitamin E), an antioxidant and chloroplast membrane bounded stress sensitive hormone that prevents peroxidation of lipids and polyunsaturated fatty acids, photo-oxidation of chloroplast, and free radical scavenger (Havaux et al., 2005; Farouk, 2011; Szarka et al., 2012).

Under stress, when the immense amount of reactive oxygen species accumulates in the plant, the concentration of membrane-bound $\alpha$-tocopherol drops, and the production of SOD, POD, CAT, proline, and phenolic compounds is severely affected, resulting in reduced growth and yield (Sadiq et al., 2016). This experiment was conducted with the aim of understanding the plant's morpho-physiological responses under low temperature stress and evaluating the effectiveness of Alpha-tocopherol foliar application to control the accumulation of antioxidants in bell peppers under stress.

\section{MATERIALS AND METHODS}

A research trial was conducted to check whether exogenously applied alpha-tocopherol acts as an effective foliar agent. The bell pepper plants were grown following hydroponic techniques in a plant growth chamber (Model MLR-351H). The experiment was conducted under complete randomized design (CRD) with three replications. Seedlings of Capsicum annuum cv. aristotle were transplanted and grown at $25{ }^{\circ} \mathrm{C}$ (daytime temperature) and $20{ }^{\circ} \mathrm{C}$ (night temperature). Exogenous application of alpha-tocopherol control (0), 25,50 , and 100 ppm was applied with the help of an atomizer after 30 days of transplantation. After one week, treated plants were subjected to chilling stress of $18{ }^{\circ} \mathrm{C}$ (day) and $15{ }^{\circ} \mathrm{C}$ (night). After seven days of low temperature stress application, plants were harvested for morphological, physiological, and biochemical study.

\section{Morphological parameters}

The length of the shoot and root of plants was measured in centimeters $(\mathrm{cm})$ using a measuring scale. An electronic weight balance (Model PX/MA 1003) was used to determine the fresh weight of the plant shoot and root in grams (g). For dryig, shoots and roots were kept in a heating oven (Model Xu058) for 24 hours at $70^{\circ} \mathrm{C}$, and the dry weight of the shoots was measured. The formula was used to calculate the leaf area $\left(\mathrm{cm}^{2}\right)$;

Area of leaf $(\mathrm{cm} 2)=$ Leaf length in $\mathrm{cm} \times$ Leaf Width in $\mathrm{cm}$ All the leaves, flowers and buds of plants were manually counted at the time of harvest.

\section{Physiological parameters}

The amounts of chlorophyll ( $a, b$, and total chlorophyll) and carotenoid from plant leaves were estimated using a technique described by (Arnon, 1949). The plant anthocyanin concentration was determined using $5 \mathrm{ml}$ of phosphate buffer ( $\mathrm{pH} 7.8$ ) and $0.25 \mathrm{~g}$ of plant material. Then centrifuged and spectrophotometrically absorbance at $600 \mathrm{~nm}$ was measured by using Model Hitachi U-1800. The technique of Barrs and Weatherley (1962) was used to determine the relative water content of the leaf, by following the given formula; 


$$
\text { RWC }=\left(\frac{\text { Fresh weight of leaf }- \text { Dry weight of leaf }}{\text { Turgid weight of leaf }- \text { Dry weight of leaf }}\right) \times 100
$$

To determine cell membrane permeability, $0.1 \mathrm{~g}$ fresh plant leaf was placed in $10 \mathrm{ml} \mathrm{H}_{2} \mathrm{O}$ in a test tube and gently stirred for 5 seconds, following the ECo value which was determined using an EC meter (Model CD98304). To determine the EC1, the filtrate was kept at $4^{\circ} \mathrm{C}$ for 24 hours. To determine the EC2, the filtrate was autoclaved for 15 minutes, and EC2 was measured by using EC meter (Model CD98304), and the CMP was calculated using the following formula;

$$
\operatorname{CMP}(\%)=\frac{\mathrm{EC}_{1}-\mathrm{EC}_{\circ}}{\mathrm{EC}_{2}-\mathrm{EC}_{\circ}} \times 100
$$

\section{Biochemical parameters}

To determine total soluble sugars, leaves were ground in methanol solution (5 mL, 80\%), centrifuged, $1 \mathrm{ml}$ sulfuric acid and $2 \mathrm{ml}$ phenol (5\%) were added, vortexed, and after 30 minutes absorbance was measured at 480 nanometers $(\mathrm{nm})$ on a spectrophotometer. Dinitrosalicylic acid reagent was used to detect reducing sugars (DNSA reagent). The

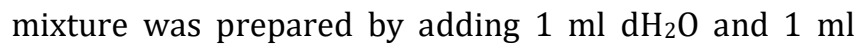
DNSA reagent in plant extrract. That mixture was placed in a water bath at $100^{\circ} \mathrm{C}$ for 15 minutes, then cool to room temperature. A spectrophotometer was used to measure the absorbance at $540 \mathrm{~nm}$. The AlCl3 colorimetric approach was used to discover flavonoids in plants. The plant extract, $0.3 \mathrm{ml} \mathrm{NaNO2} \mathrm{(5 \% ),} \mathrm{and} 0.3$ m Aluminium chloride $(10 \%)$ was added in a test tube and gently shaked for a few minutes. Then $2 \mathrm{ml}$ of sodium hydroxide ( $1 \mathrm{M}$ ) was added, and after 5 minutes the absorbance was measured on a spectrophotometer at $510 \mathrm{~nm}$. Folin-Ciocateu reagent was used to determine the phenolic content of the bell pepper plant. Folin reagent $(1 \mathrm{ml})$ and $\mathrm{Na} 2 \mathrm{CO} 3(1 \mathrm{ml})$ were added to $0.5 \mathrm{ml}$ plant extract. At $40^{\circ} \mathrm{C}$, the mixture was placed in a water bath until the colour emergence, then absorbance was measured at $765 \mathrm{~nm}$. The Bradford technique was used to determine total soluble protein (1976). Plant extract $(0.1 \mathrm{ml})$ was combined with $2 \mathrm{ml}$ Bradford reagent and absorbance was measured at $590 \mathrm{~nm}$ on spectrophotometer. The total free amino acid in bell pepper plants was determined using the Yemm et al. (1955) technique. The plant material (1 g) was ground in $10 \mathrm{ml}$ of phosphate buffer ( $\mathrm{pH}$ 7.1) and centrifuged to get the extract. $0.5 \mathrm{ml}$ centrifuged material was added to $0.5 \mathrm{ml}$ of $10 \%$ pyrimidine, $0.5 \mathrm{ml} 2 \%$ ninhydrin, and the solution was water bathed for 30 minutes before checking the absorbance at $570 \mathrm{~nm} .0 .1 \mathrm{ml}$ plant extract, add $2 \mathrm{ml}$ phosphate buffer, $0.1 \mathrm{ml} \mathrm{H}_{2} \mathrm{O}_{2}(5.9 \mathrm{mM})$ was taken to determine the activity of the CAT (catalase) enzyme. The absorbance of the mixture was measured at $240 \mathrm{~nm}$. To test the activity of Peroxidase enzyme (POD) in plants, mixture of $0.1 \mathrm{ml}$ plant extract, $1.5 \mathrm{ml}$ potassium buffer, $0.5 \mathrm{ml}$ guaiacol, and $1 \mathrm{ml} \mathrm{H}_{2} \mathrm{O}_{2}$ was prepared and measured the absorbance at $470 \mathrm{~nm}$ using a spectrophotometer. To determine SOD enzyme activity in plants, the mixture was prepared by adding plant extract with phosphate buffer $(0.5 \mathrm{ml}), 0.1 \mathrm{ml} 100 \mathrm{mM}$ methionine, $0.1 \mathrm{ml} 2 \mathrm{mM}$ riboflavin, $0.1 \mathrm{ml}$ plant extract, and $0.1 \mathrm{ml} \mathrm{NBT}(1 \mathrm{mM})$. After exposing the combination to light for 15 minutes, the absorbance was measured at $560 \mathrm{~nm}$. To test the activity of the ascorbate peroxidase (APX) enzyme in plants, 100 liters of plant extract with 1 liter of distilled water, 100 liters of EDTA, 100 liters of ascorbic acid, 600 liters of $\mathrm{H}_{2} \mathrm{O}_{2}$ was used to prepare the mixture, readings of the absorbance at $290 \mathrm{~nm}$ was calculated by using spectrophotometer. Velikova et al. (2000) used a technique to determine the $\mathrm{H}_{2} \mathrm{O}_{2}$ content in plants, by following that technique the mixture was prepared by adding $1 \mathrm{ml}$ plant extract, $1 \mathrm{ml} \mathrm{KI}$ at $1 \mathrm{M}$ concentration, $100 \mathrm{~L}$ phosphate buffer, kept at room temperature for half an hour and absorbance was measured using a spectrophotometer at $390 \mathrm{~nm}$ wavelength. The quantity of MDA in the sample was determined using Heath and Packer (1968) technique of $0.5 \%$ TCA in $20 \%$ TBA. The Bates et al. (1973) technique was used to determine the content of proline in the plant. $1 \mathrm{ml}$ of $3 \%$ sulfosalicylic acid, $1 \mathrm{ml}$ glacial acetic acid (100\%), and $1 \mathrm{ml}$ ninhydrin were added to $1 \mathrm{ml}$ plant extract, and the mixture was immersed in a water bath at $100{ }^{\circ} \mathrm{C}$ for 30 minutes. Then $4 \mathrm{~mL}$ of toluene was added and the mixture was shaked carefully until the two layers formed. The top layer was taken to measure the absorbance at $520 \mathrm{~nm}$ with the help of spectrophotometer.

\section{RESULTS}

\section{Morphological parameters}

Fresh and dried weight of shoots reduced considerably when exposed to high temperatures. When alphatocopherol was administered exogenously, stress was not as much effective; however, the foliar treatment decreased stress and resulted in an increase in shoot length. The effects of foliar alpha-tocopherol 
concentrations $(25,50$, and $100 \mathrm{ppm})$ on stress-induced damage were substantial. When compared to control plants, $100 \mathrm{ppm}$ alpha-tocopherol was the most effective in minimizing stress effects and increasing shoot length in bell pepper (Figure 1). Under low temperature stress, bell pepper root length, fresh and dried weight were all reduced due to stress. Plants given alpha-tocopherol as a foliar spray demonstrated tolerance to the stress. Alphatocopherol concentrations of $100 \mathrm{ppm}$ were shown to be effective in lowering stress effects and improving root length, fresh and dry weight (Figure 1). Plants under stress showed a decrease in leaf area. In comparison to control plants, alpha-tocopherol treated plants had more leaf area. Alpha-tocopherol was shown to be beneficial in lowering stress, and plants treated with $100 \mathrm{ppm}$ alphatocopherol had more leaf area than non-treated plants of bell pepper (Figure 2). Temperature stress reduced the amount of leaves, buds, and flowers per plant substantially. When compared to plants grown under control conditions, alpha-tocopherol treatment $(25,50$, and $100 \mathrm{ppm}$ ) proved effective in eliminating stressinduced effects. When comparing plants treated with $100 \mathrm{ppm}$ alpha-tocopherol to control and various levels of treatment, a clear increase in the number of leaves, buds, and flowers per plant was observed (Figure 2).
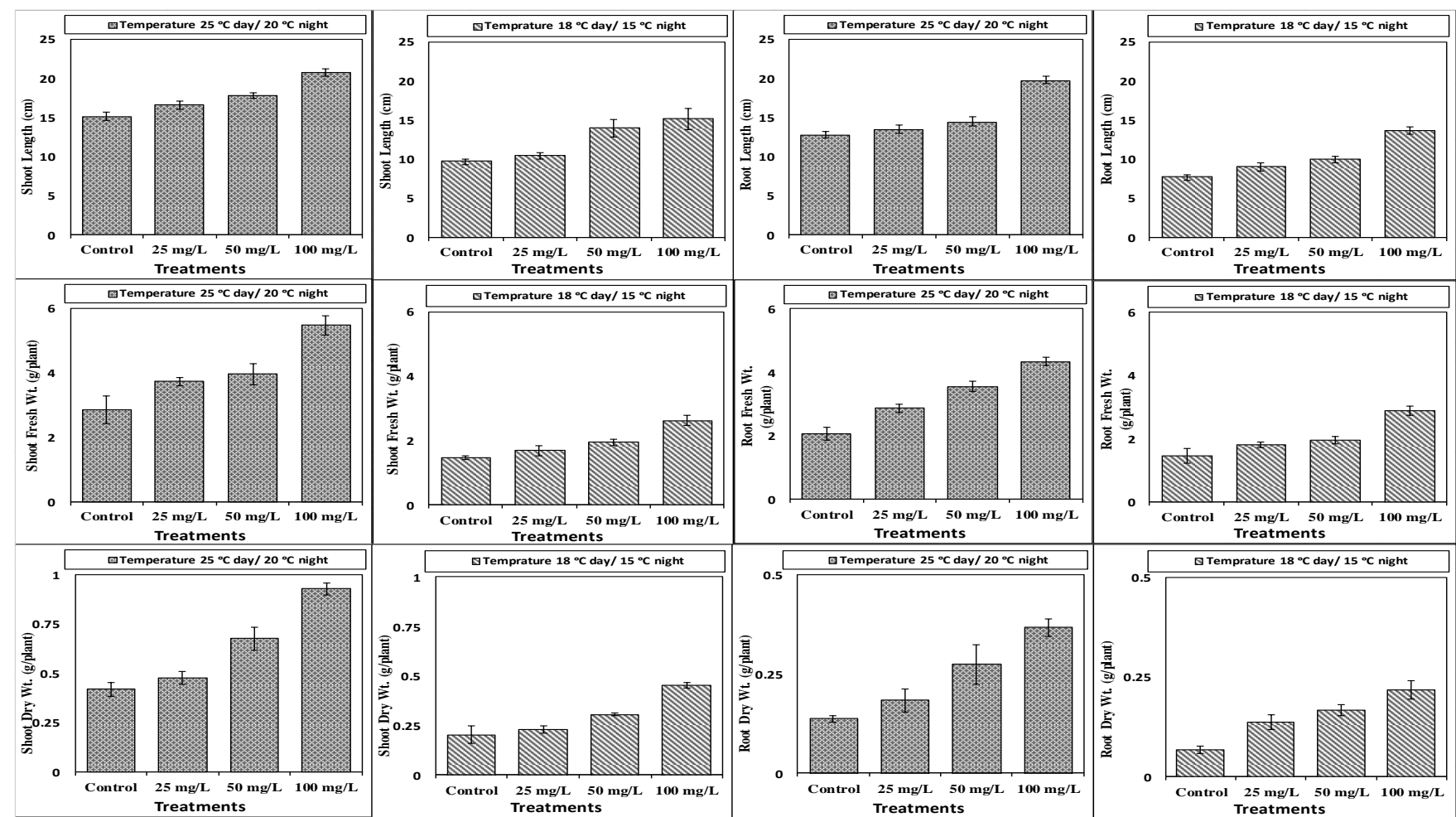

Figure 1. Shoot length, fresh and dry weight, root length, fresh and dry weight of bell pepper (Capcicum annuum L.) treated with different levels of alpha-tocopherol (control, 25, 50,100 mg/L) as foliar agent under temperature stress.

\section{Physiological parameters}

Reduced chlorophyll content was observed in the fresh leaves of a bell pepper plant when temperature stress was applied. Stress-induced effects were reduced by alpha-tocopherol application. Plants treated with alpha-tocopherol showed increased chlorophyll a content as compared to control plants under low temperature stress. Foliar application of -tocopherol at
$100 \mathrm{ppm}$ levels showed better results in reducing stress (Figure 2). In the fresh leaves of bell pepper, chlorophyll b content decreased significantly when stress was applied. When a plant is subjected to low temperature stress, its chlorophyll content decreases. Exogenously applied alpha-tocopherol at all levels were found beneficial in reducing the stress effect caused by temperature stress (Figure 2). 

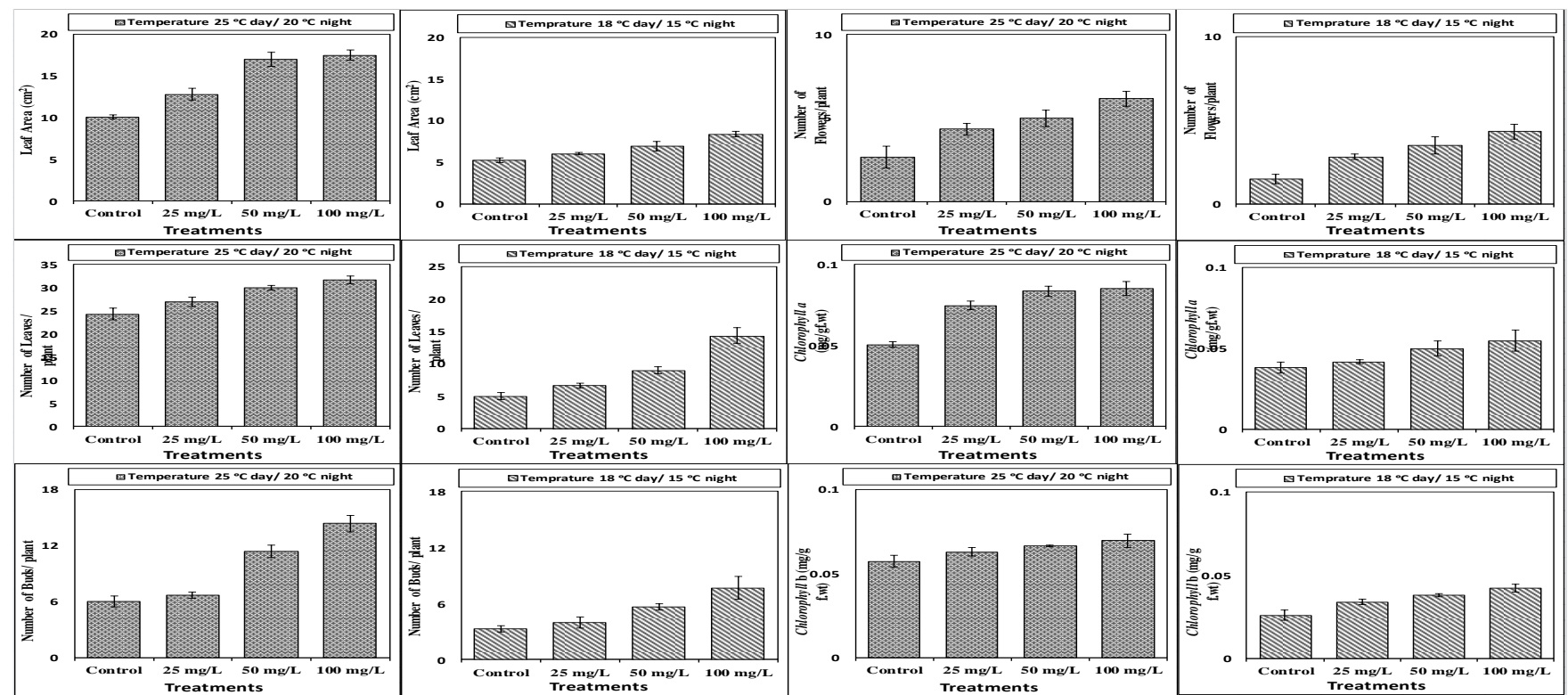

Figure 2. Leaf area, number. of leave, number of buds, number of flower, chlorofhyll $a$ and chlorophyll $b$ of bell pepper (Capcicum annuum L.) treated with varying levels of alpha-tocopherol (control, 25, 50, $100 \mathrm{mg} / \mathrm{L}$ ) as foliar agent under temperature stress.

\section{Biochemical Parameters}

The foliar application was effective and increased the chlorophyll $\mathrm{a} / \mathrm{b}$ ratio in the plants treated with alphatocopherol foliar under low temperature stress (Figure 3). Carotenoid content in fresh leaves of a bell pepper plant was reduced significantly when low temperature stress was applied. Alpha-tocopherol was effective in enhancing carotenoid content. Of various alphatocopherol levels, 25 and 50 ppm increased carotenoid content as compared to the others under stress conditions (Figure 3).
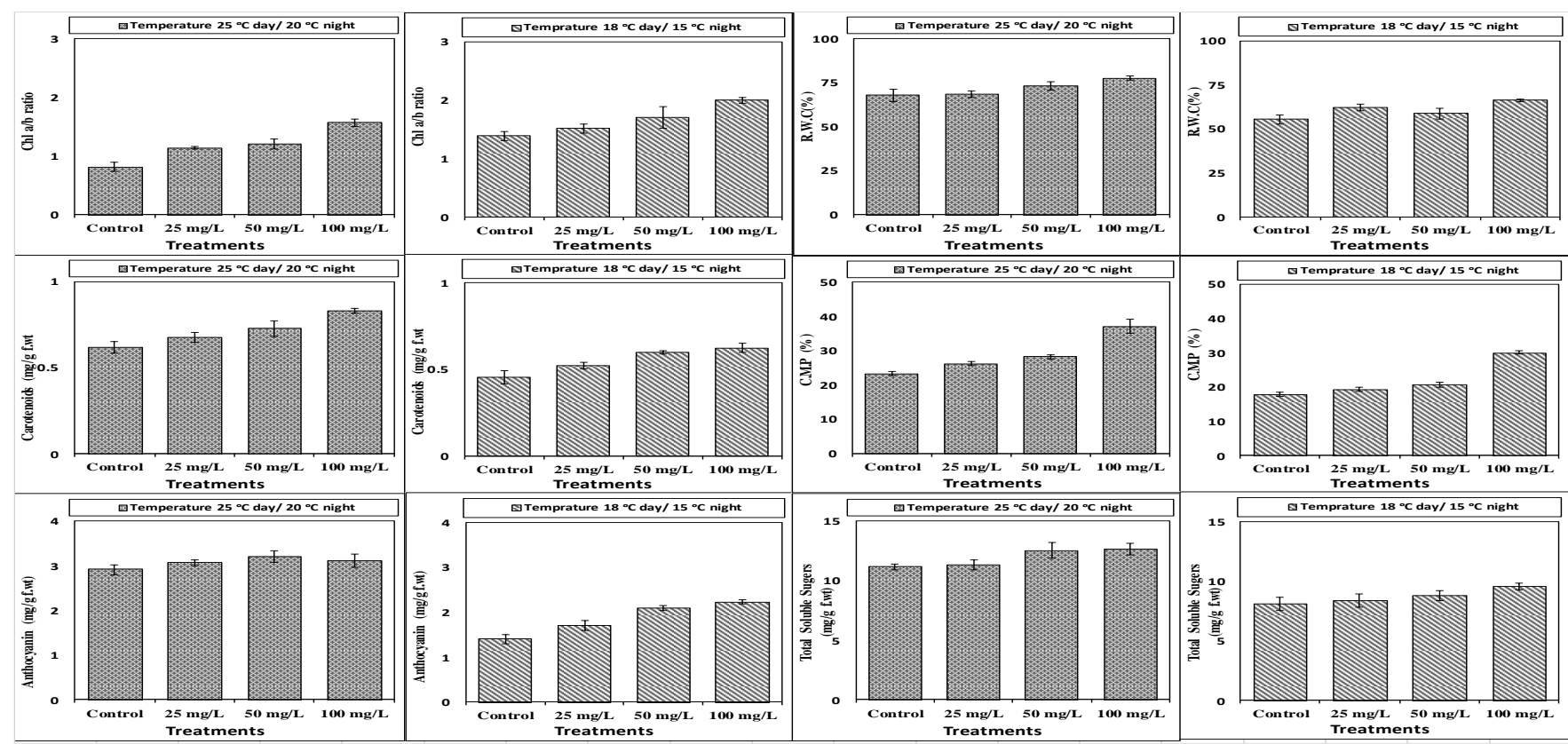

Figure 3. Chl $a / b$ ratio, carotenoids, anthocyanin, R.W.C, C.M.P and total soluble sugars of bell pepper (Capcicum annuum L.) treated with different levels of alpha-tocopherol (control, 25, 50, $100 \mathrm{mg} / \mathrm{L}$ ) as foliar agent under temperature stress. 
Anthocyanin content was reduced under temperature stress significantly. Application of alpha-tocopherol caused a significant increase in the plant carotenoid content under temperature stress when compared to the plants not treated with alpha-tocopherol. When plants were treated with 100ppm alpha-tocopherol exogenously, their anthocyanin content was significantly higher than in control plants (Figure 3). Relative water content is significantly reduced under temperature stress. When temperature stress is applied (Figure 3), the relative water content of bell peppers increased when treated with alphatocopherol in comparison to plants that were not treated with $\alpha$-tocopherol.100ppm of alpha-tocopherol improves the relative water content of the bell pepper plant. Cell membrane permeability (CMP) in the fresh leaves of a bell pepper plant is reduced under temperature stress. Exogenous application of alpha-tocopherol improved CMP as observed in plants treated with $\alpha$-tocopherol in comparison to plants not treated with the exogenous application. Among different levels, 100ppm improved more CMP than other levels of alpha-tocopherol treatment under stress (Figure 3). The total soluble sugar content in the fresh leaves of bell pepper plants was reduced significantly when temperature stress was applied. Increased soluble sugar content was observed in plants treated with the alpha-tocopherol exogenous application. Under low temperature stress, 100ppm exogenous application eliminates stress-induced effects and increased the content of soluble sugars (Figure 3). Under temperature stress, the total reducing sugar content in fresh leaves of bell pepper plants was significantly reduced. Among the levels of $\alpha$-tocopherol applied as a foliar spray, plants treated with $100 \mathrm{ppm}$ alpha-tocopherol showed increased total reducing sugar content as compared to control plants under stress (Figure 4).

An increase in flavonoid content was observed when temperature stress was applied. Used as a foliar spray, it reduced the low temperature stress effect. Exogenous application of $100 \mathrm{ppm}$ alpha-tocopherol resulted in a significant increase in the flavonoids content of the stressed plant (Figure 4). Phenolic contents in fresh leaves of bell pepper plants increased under temperature stress. Plants treated with $100 \mathrm{ppm}$ alpha-tocopherol had lower phenolic content when compared to other levels of foliar and plants grown under temperature stress (Figure 4).Total soluble protein decreased under temperature stress in fresh leaves of bell pepper plants. Plant total soluble protein concentration was significantly reduced under low temperature stress. Foliar application of alphatocopherol reduced the temperature stress effect and increased the content of total soluble protein observed in plants treated with $100 \mathrm{ppm}$ alpha-tocopherol as compared to plants grown under control conditions under stress (Figure 4).
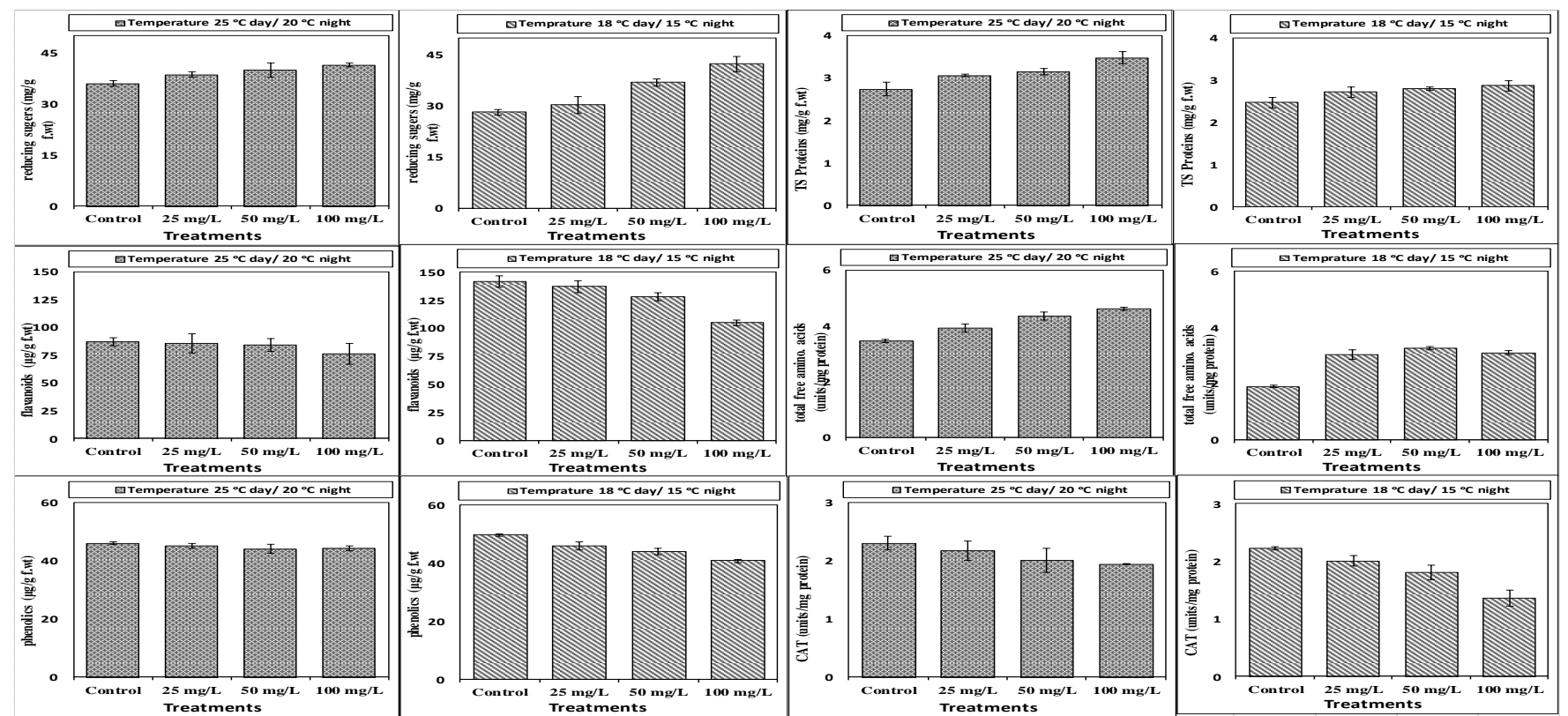

Figure 4. Total reducing sugars, flavonoids, phenolics, total soluble proteins and CAT activity (catalase per oxidase) of bell pepper (Capcicum annuum L.) treated with different levels of alpha-tocopherol (control, 25, 50, $100 \mathrm{mg} / \mathrm{L}$ ) as foliar agent under temperature stress. 
Under low temperature stress, total free amino acid decreased in the fresh leaves of bell pepper plants. An increase in total free amino acid content was observed in $100 \mathrm{ppm}$ alpha-tocopherol treated plants under stress as compared to other levels of treatments (Figure 4). The activity of catalase (CAT) increased with temperature in bell pepper plants. The catalase enzyme is produced in response to an increase in reactive oxygen species (ROS) in a stressed plant. It was observed that foliar application of alpha-tocopherol reduced temperature stress effects and plants treated with $100 \mathrm{ppm}$ alphatocopherol had improved catalase activity (Figure 4). The activity of POD increased with the temperature in bell pepper plants. Foliar application of alpha-tocopherol improved the POD activity. Plants treated with 50 and
100 ppm alpha-tocopherol showed high peroxidase activity as compared to the others (Figure 5).

The activity of the SOD enzyme increased when temperature stress was applied. Foliar application of alpha-tocopherol was effective and reduced stressinduced effects in bell pepper plants. It was observed that plants treated with $100 \mathrm{ppm}$ alpha-tocopherol improved SOD activity as compared to other levels under temperature stress (Figure 5). The activity of the APX (Ascorbate peroxidase) enzyme increased under temperature stress in bell pepper plants. Temperature stress increased APX activity observed in plants. Plants treated with $100 \mathrm{ppm}$ alpha-tocopherol showed a decrease in the activity of the APX in comparison to the control (Figure 5).
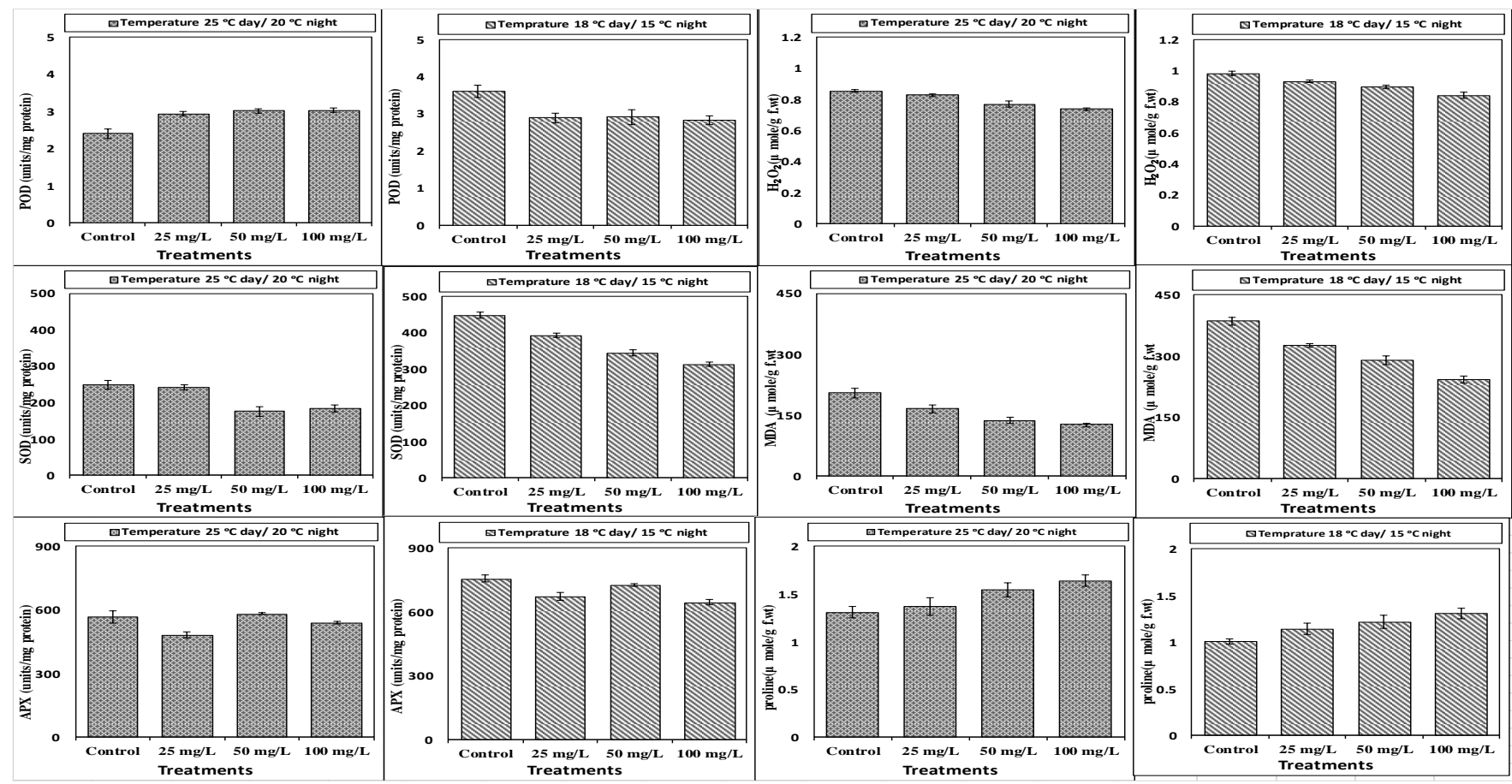

Figure 5. POD, SOD, APX. $\mathrm{H}_{2} \mathrm{O}_{2}$, MDA and proline of bell pepper (Capcicum annuum L.) treated with different levels of alpha-tocopherol (control, 25, 50, $100 \mathrm{mg} / \mathrm{L}$ ) as foliar agent under temperature stress.

The $\mathrm{H}_{2} \mathrm{O}_{2}$ concentration increased under temperature stress in bell pepper plants. Foliar application of alphatocopherol lowered the $\mathrm{H}_{2} \mathrm{O}_{2}$ concentration in bell pepper plants (Figure 5). The malondialdehyde concentration in plants increased under temperature stress. Plants treated with alpha-tocopherol reduced stress effects. Plants treated with 100ppm alphatocopherol foliar application have a reduced concentration of MDA under stress (Figure 5). In bell pepper plants, proline content increased when temperature stress was applied. Foliar application of alpha-tocopherol played a significant role in reducing temperature stress effects. Proline, a stress indicator, is reduced in $100 \mathrm{ppm}$ alpha-tocopherol treated plants as compared to plants under control conditions when temperature stress is applied (Figure 5). Stress affected the metabolites in plants, ion leakage decreased, and antioxidants hunted the reactive oxygen species (ROS). Under stress, the production of antioxidants increases due to increased oxidative stress. Foliar application of 
alpha-tocopherol improved the plant growth, sugar, protein, and amino acid contents by reducing oxidative stress.

\section{DISCUSSION}

During the life cycle of crops, they are exposed to different environmental stresses. Stress adversely affects the development and growth of plants. Plants under stress have a disturbed metabolic rate and produce less biomass (Wei et al., 2014). alphatocopherol is a membrane-bound antioxidant of plants and is present in the chloroplast (Orabi and Abdelhamid, 2016). When plants are under stress, alpha-tocopherol controls redox reactions in the chloroplast and prevents the membrane from degradation (Munné-Bosch, 2005). In the present study, low temperature stress negatively affects the shoot length, fresh and dry weight of the shoot and root length, as well as the fresh and dry weight of the root. Under stress, a reduction in the number of leaves, buds, and flowers in bell pepper plants is clearly observed. Alpha-tocopherol has a significant effect and improves root and shoot length. The fresh and dry mass of root and shoot increased in alphatocopherol treated plants. In stress conditions, upgradation in growth is related to the higher protein content available to the plant under tocopherol treatment. Similarly, alpha-tocopherol prompted growth was reported in faba beans (Semida et al., 2014). Applying alpha-tocopherol levels of $25 \mathrm{ppm}, 50 \mathrm{ppm}$, and $100 \mathrm{ppm}$ as foliar was effective in improving growth. In the present study, reduced RWC, CMP, chlorophyll a, b, and carotenoid were observed. Temperature stress has severe effects on plant water relations. Membrane deformation and ion gradient imbalance caused by ion leakage have been observed in stressed plants. It was reported that in bell peppers, under low temperature stress, reduced chlorophyll content was present. Carotenoids and chlorophyll degrade under low temperature stress (León-Chan et al., 2017). Chilling has a destructive effect on cucumber seedlings and lower chlorophyll contents, CMP, and RWC were observed in cucumber seedlings (Seydpour and Sayyari, 2016). In tomato seedlings, chilling stress leads to higher solute leakage and the eventual death of plant leaves (Senaratna et al., 1988). Foliar application of alpha-tocopherol reduced the temperature stress in bell pepper plants and higher chlorophyll content, improved CMP and RWC were observed in plants under treatment in comparison to those grown in a controlled environment. Similar results of alpha-tocopherol foliar application in reducing stress were observed in Vigna radiata (Sadiq et al., 2017). The chlorophyll content of flag leaf wheat grown under stress conditions decreased significantly, and the application of alpha-tocopherol improved the chlorophyll content (Farouk, 2011). Alphatocopherol improves the growth rate, chlorophyll, RWC, and antioxidant activity by inhibiting the reactive oxygen species accumulation in bell pepper plants. In the present study, under low temperature stress in bell pepper plants, total sugar, reducing sugar, and total soluble proteins decreased. It was reported that carbohydrate contents decrease in plant parts under low night temperatures in bell peppers (Shaked et al., 2004). In the present experimental study, alpha-tocopherol exogenous application lessens the temperature stress effects in bell pepper plants and a higher content of sugars and protein is observed in plants treated with alpha-tocopherol when compared to plants under control. Similarly, in Linum usitatissimum plants, an increase in total carbohydrate and total protein content treated with alpha-tocopherol foliar application was reported (Sadak, 2014). Increased proline, flavonoid, and phenolic content were observed in the present study. Under low temperatures, oxidative stress increases and the plant increases its osmolytes to protect the plant from oxidation. Foliar application of alpha-tocopherol improved the plant's proline, flavonoid, and phenolic content. Exogenous application of soy bean-tocopherol improved the concentrations of proline, soluble sugars, and free amino acids under stress conditions (Mostafa et al., 2015). In two cultivars of Vicia faba, an increased proline content was observed under stress, and foliar application of alpha-tocopherol lowered stress-induced effects and improved the proline content (Orabi and Abdelhamid, 2016). In the present study, an increase in H2O2, MDA, SOD, CAT, POD, and APX enzymatic antioxidants under temperature stress was observed. Whereas alpha-tocopherol foliar application improved the activity of catalase, POD, and APX enzymes and reduced MDA and $\mathrm{H} 2 \mathrm{O} 2$ under temperature stress, CAT, POD, and APX enzymatic antioxidants are effective biomolecules that prevent the plant from cellular damage. In cucumbers, increased $\mathrm{H}_{2} \mathrm{O}_{2}$ content, CAT, POD, SOD, and APX activity were reported under chilling stress (Yang et al., 2011). Similarly, under low temperature stress, ROS (reactive 
oxygen species) accumulate in sweet pepper plants, and a higher content of $\mathrm{H}_{2} \mathrm{O}_{2}$ and increased activity of APX reported (Airaki et al., 2012). Increased lipid peroxidation, activity of CAT and POD were reported in three flax cultivars under stress. The application of alpha-tocopherol to the skin reduces the effects of stress and increases the activity of the antioxidants CAT and POD (El-Bassiouny and Sadak, 2015). In bell peppers, chilling stress produces oxidative stress and an increased $\mathrm{H}_{2} \mathrm{O}_{2}$ content, CAT, POD, SOD, and APX activity were reported. Antioxidants control the accumulation of ROS. Their chelation with metal ions lowers the formation of excessive ROS by reducing their catalytic activity. Foliar application of hormones reduces the $\mathrm{H}_{2} \mathrm{O}_{2}$ content and improves the activity of CAT, POD, SOD, and APX (Li et al., 2015).

It was concluded from the results of the current experiment that low temperature stress reduced the growth and high oxidative stress produced under stress. Foliar application of alpha-tocopherol was beneficial in regulating growth and improving the antioxidant potential of the bell pepper plants under low temperature stress.

\section{REFERENCES}

Airaki, M., M. Leterrier, R. M. Mateos, R. Valderrama, M. Chaki, J. B. Barroso, L. A. Del Rio, J. M. Palma and F. J. Corpas. 2012. Metabolism of reactive oxygen species and reactive nitrogen species in pepper (Capsicum annuum L.) plants under low temperature stress. Plant, Cell and Environment, 35: 281-95.

Ali, Q., M. Ashfaq and M. T. I. Khan. 2016. An Economic Analysis Of Off-Season Capsicum/Bell Pepper Production In Punjab, Pakistan. ARPN Journal of Agriculture and Biological Science, 11: 424-30.

Arnon, D. I. 1949. Copper enzymes in isolated chloroplasts. Polyphenoloxidase in Beta vulgaris. Plant physiology, 24: 1-18.

Barrs, H. and P. Weatherley. 1962. A re-examination of the relative turgidity technique for estimating water deficits in leaves. Australian journal of biological sciences, 15: 413-28.

Bates, L. S., R. P. Waldren and I. Teare. 1973. Rapid determination of free proline for water-stress studies. Plant and soil, 39: 205-07.

El-Bassiouny, H. and M. S. Sadak. 2015. Impact of foliar application of ascorbic acid and $\alpha$-tocopherol on antioxidant activity and some biochemical aspects of flax cultivars under salinity stress. Acta Biológica Colombiana, 20: 209-22.

Farouk, S. 2011. Ascorbic acid and $\alpha$-tocopherol minimize salt-induced wheat leaf senescence. Journal of Stress Physiology and Biochemistry, 7: 413-19.

Havaux, M., F. Eymery, S. Porfirova, P. Rey and P. Dörmann. 2005. Vitamin E protects against photoinhibition and photooxidative stress in Arabidopsis thaliana. The Plant Cell, 17: 3451-69.

Heath, R. L. and L. Packer. 1968. Photoperoxidation in isolated chloroplasts: I. Kinetics and stoichiometry of fatty acid peroxidation. Archives of biochemistry and biophysics, 125: 189-98.

Jing, P., D. Wang, C. Zhu and J. Chen. 2016. Plant physiological, morphological and yield-related responses to night temperature changes across different species and plant functional types. Frontiers in plant science, 7: 1774-81.

Kantar, M. B., J. E. Anderson, S. A. Lucht, K. Mercer, V. Bernau, K. A. Case, N. C. Le, M. K. Frederiksen, H. C. DeKeyser and Z.-Z. Wong. 2016. Vitamin variation in Capsicum spp. provides opportunities to improve nutritional value of human diets. PLoS One, 11: e0161464.

Khan, M. T. I., A. Qamar, A. Muhammad and W. Muhammad. 2017. Economic analysis of open field chilli (Capsicum annuum L.) production in Punjab, Pakistan. Journal of Experimental Biology and Agricultural Sciences, 5: 120-25.

León-Chan, R. G., M. López-Meyer, T. Osuna-Enciso, J. A. Sañudo-Barajas, J. B. Heredia and J. León-Félix. 2017. Low temperature and ultraviolet-B radiation affect chlorophyll content and induce the accumulation of UV-B-absorbing and antioxidant compounds in bell pepper (Capsicum annuum) plants. Environmental and Experimental Botany, 139: 143-51.

Li, J., P. Yang, Y. Gan, J. Yu and J. Xie. 2015. Brassinosteroid alleviates chilling-induced oxidative stress in pepper by enhancing antioxidation systems and maintenance of photosystem II. Acta Physiologiae Plantarum, 37: 1-11.

Li, X.-G., X.-M. Wang, Q.-W. Meng and Q. Zou. 2004. Factors limiting photosynthetic recovery in sweet pepper leaves after short-term chilling stress 
under low irradiance. Photosynthetica, 42: 25762.

Liu, P., Q.-w. Meng, Q. Zou, S.-j. Zhao and Q.-z. Liu. 2001. Effects of cold-hardening on chilling-induced photoinhibition of photosynthesis and on xanthophyll cycle pigments in sweet pepper. Photosynthetica, 39: 467-72.

Mateos, R. M., A. Jiménez, P. Román, F. Romojaro, S. Bacarizo, M. Leterrier, M. Gómez, F. Sevilla, L. A. Del Río and F. J. Corpas. 2013. Antioxidant systems from pepper (Capsicum annuum L.): Involvement in the response to temperature changes in ripe fruits. International Journal of Molecular Sciences, 14: 9556-80.

Mostafa, M. R., S. S. Mervat, R. E.-L. Safaa, M. A. E. Ebtihal and T. A. Magdi. 2015. Exogenous $\alpha$-tocopherol has a beneficial effect on Glycine max (L.) plants irrigated with diluted sea water. The Journal of Horticultural Science and Biotechnology, 90: 195202.

Munné-Bosch, S. 2005. The role of $\alpha$-tocopherol in plant stress tolerance. Journal of plant physiology, 162: 743-48.

Oertli, J. 1987. Exogenous application of vitamins as regulators for growth and development of plantsA review. Zeitschrift für Pflanzenernährung und Bodenkunde, 150: 375-91.

Orabi, S. A. and M. T. Abdelhamid. 2016. Protective role of $\alpha$-tocopherol on two Vicia faba cultivars against seawater-induced lipid peroxidation by enhancing capacity of anti-oxidative system. Journal of the Saudi Society of Agricultural Sciences, 15: 145-54.

Pyshnaya, O., M. Mamedov, E. Belavkin, E. Kozar, E. Dzhos and A. Matyukina. 2016. Resistance of sweet pepper genotypes to abiotic stresses in grpwing conditions of low-capacity hydroponics. Agricultural biology, 51: 100-10.

Qureshi, H., S. S. Hamid, S. S. Ali, J. Anwar, A. A. Siddiqui and N. A. Khan. 2015. Cytotoxic effects of aflatoxin B1 on human brain microvascular endothelial cells of the blood-brain barrier. Medical mycology, 53: 409-16.

Sadak, M. S. 2014. Role of ascorbic acid and $\alpha$ tocopherol in alleviating salinity stress on flax plant (Linum usitatissimum L.). Journal of Stress Physiology \& Biochemistry, 10: 93-101.

Sadiq, M., N. A. AKRAM and M. Ashraf. 2017. Foliar applications of alpha-tocopherol improves the composition of fresh pods of Vigna radiata subjected to water deficiency. Turkish Journal of Botany, 41: 244-52.

Sadiq, M., N. A. Akram and M. T. Javed. 2016. Alphatocopherol alters endogenous oxidative defense system in mung bean plants under water-deficit conditions. Pakistan journal of Botany, 48: 217782.

Semida, W., R. Taha, M. Abdelhamid and M. Rady. 2014. Foliar-applied $\alpha$-tocopherol enhances salttolerance in Vicia faba L. plants grown under saline conditions. South African Journal of Botany, 95: 24-31.

Senaratna, T., C. E. Mackay, B. D. McKersie and R. Fletcher. 1988. Uniconazole-induced chilling tolerance in tomato and its relationship to antioxidant content. Journal of plant physiology, 133: 56-61.

Seydpour, F. and M. Sayyari. 2016. Chilling injury in cucumber seedlings amelioration by methyl salicylate. International Journal of Vegetable Science, 22: 432-41.

Shah, H., Y. Tahira, M. Fahim, S. Hameed and M. Haque. 2009. Prevalence, occurrence and distribution of Chili veinal mottle virus in Pakistan. Pakistan journal of Botany, 41: 955-65.

Shaked, R., K. Rosenfeld and E. Pressman. 2004. The effect of low night temperatures on carbohydrates metabolism in developing pollen grains of pepper in relation to their number and functioning. Scientia Horticulturae, 102: 29-36.

Shrestha, R. B., W.-C. Huang and R. Ghimire. 2014. Production efficiency of smallholder vegetable farms in Ilam district, Eastern Hill, Nepal. American-Eurasian Journal of Agricultural and Environmental Sciences, 14: 150-54.

Szarka, A., B. Tomasskovics and G. Bánhegyi. 2012. The ascorbate-glutathione- $\alpha$-tocopherol triad in abiotic stress response. International Journal of Molecular Sciences, 13: 4458-83.

Velikova, V., I. Yordanov and A. Edreva. 2000. Oxidative stress and some antioxidant systems in acid raintreated bean plants: Protective role of exogenous polyamines. Plant science, 151: 59-66.

Wang, W., B. Vinocur and A. Altman. 2003. Plant responses to drought, salinity and extreme temperatures towards genetic engineering for stress tolerance. Planta, 218: 1-14. 
Wang, Y. and Y. Liu. 2010. Progress in plant autophagy. China Journal of Cell Biology, 32: 677-89.

Wei, W., N. Smith, X. Wu, H. Kim, J. Seravalli, O. Khalimonchuk and J. Lee. 2014. YCF1-mediated cadmium resistance in yeast is dependent on copper metabolism and antioxidant enzymes. Antioxidants and Redox Signaling, 21: 1475-89.

Yang, H., F. Wu and J. Cheng. 2011. Reduced chilling injury in cucumber by nitric oxide and the antioxidant response. Food chemistry, 127: 1237-42.

Yemm, E., E. Cocking and R. Ricketts. 1955. The determination of amino-acids with ninhydrin. Analyst, 80: 209-14.

Zhai, Y., M. Guo, H. Wang, J. Lu, J. Liu, C. Zhang, Z. Gong and M. Lu. 2016. Autophagy, a conserved mechanism for protein degradation, responds to heat, and other abiotic stresses in Capsicum annuum L. Frontiers in plant science, 7: 131-46.

\section{CONFLICT OF INTEREST}

The authors have not declared any conflict of interests.

\section{AUTHORS CONTRIBUTIONS}

All the authours equelly contributed in research as well as helped in manuscript draftingand analyzing the data

Publisher's note: EScience Press remains neutral with regard to jurisdictional claims in published maps and institutional affiliations.

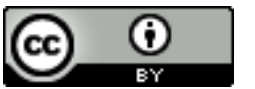

Open Access This article is licensed under a Creative Commons Attribution 4.0 International License, which permits use, sharing, adaptation, distribution and reproduction in any medium or format, as long as you give appropriate credit to the original author(s) and the source, provide a link to the Creative Commons license and indicate if changes were made. The images or other third-party material in this article are included in the article's Creative Commons license, unless indicated otherwise in a credit line to the material. If material is not included in the article's Creative Commons license and your intended use is not permitted by statutory regulation or exceeds the permitted use, you will need to obtain permission directly from the copyright holder. To view a copy of this license, visit http://creativecommons.org/licenses/by/4.0/. 